\title{
PERTUMBUHAN TANAMAN SENGON BUTO (Enterolobium cyclocrpum Griseb) FASE TINGKATAN SEMAI DENGAN MEDIA OVERBURDEN
}

\section{THE GROWTH OF SENGON BUTO (Enterolobium cyclocrpum Griseb) PLANTS PHASE OF SEEDLING LEVEL WITH OVERBURDEN MEDIA}

\author{
Sukariyan $^{1 *}$, Marjenah², Wawan Kustiawan², Wahjuni Hartati², Garini Widosari ${ }^{3}$ \\ ${ }^{1}$ Politeknik Pertanian Negeri Samarinda, Kampus Gunung Panjang, Jl. Samratulangi, \\ Samarinda, Indonesia \\ 2Universitas Mulawarman Kampus Gunung Kelua JI. M Yamin. Samarinda. Indonesia \\ ${ }^{3}$ Politeknik Negeri Samarinda Kampus Gunung Panjang. Jl. Cipto Mangunkusumo. \\ Samarinda Seberang.Indonesia \\ *Sukariyan971@gmail.com
}

\begin{abstract}
Plant growth is known as increasing volume of the diameter and height of the plant stem. Overburden material after coal mining has conditions where the soil structure is damaged, rock fragmentation is mixed and there is no layer of organic matter. The research objective is to determine the suitability of plant growth in several growing media. The research method is done by planting test in a nursery with plant growth media consisting of top soil material as a control, a mixing of overburden material with foliar fertilizer from sengon buto plants, and overburden growing media, the three media were compared. Results of significance were less than 0.05. The growth medium affects the growth of sengon buto (Enterolobium cyclocarpum Griseb) seedlings.
\end{abstract}

Keywords : Leaf fertilizer, Overburden media, Seedling growth, Sengon buto.

\section{PENDAHULUAN}

$\begin{array}{cr}\text { Pertumbuhan } & \text { tanaman } \\ \text { merupakan pertambahan } & \text { yang }\end{array}$ menunjukan riap diameter dan riap tinggi (Murtinah., Dkk, 2015). Pertumbuhan diameter dan tinggi tanaman di pengaruhi besaran dosis pupuk yang diberikan di lahan pasca tambang batubara (Mansur dan Adiwicaksono, 2013). Tanaman Sengon Buto (Enterolobium cyclocarpum Griseb.) merupakan jenis tanaman cepat tumbuh dan adaptif pada lahan pasca tambang (Wasis dan Alkautsar, 2019). Lahan pasca tambang batubara umumnya berupa timbunan material lapisan penutup (overburden) yang kondisi struktur tanahnya rusak, fragmentasi batuan tercampur batubara tanpa lapisan bahan organik (Sudarmadji dan Hartati, 2013). Kesesuaian media tumbuh dan keberhasilan hidup (pertumbuhan) tanaman sengon buto (Enterolobium cyclocarpum Griseb) di fase tingkatan semai dengan membandingkan beberapa media tumbuh di persemaian dan media material lahan pasca tambang.

\section{METODOLOGI}

Perlakuan media tumbuh

Material media tumbuh tanaman diambil dari dua tempat yang berbeda yaitu yang pertama media tumbuh yang diambil dari material tanah timbunan buangan (overburden) kegiatan pertambangan batubara, sedangkan yang kedua media tumbuh diambil dari lapisan tanah atas (top soil) dibawah tegakan hutan.

a) Media tumbuh top Soil

Perlakuan media dengan memisahkan bagian-bagian tanah dari kotoran (ranting, akar, daun), hal ini untuk memudahkan memasukkan media top soil ke polybag.

b) Media tumbuh overburden

Perlakuan media dengan menghaluskan material untuk mendapatkan besaran butiran- 
butiran tanah yang seragam kedalam polybag

c) Media tumbuh overburden+pupuk daun dari sengon buto

Perlakuan media 5:1 (5 material overburden:1 pupuk daun dari sengon buto yang sudah dikomposkan).

\section{Penanaman bibit di polybag}

Pelaksanaan penanaman bibit ketika bakal bibit berupa kecambah yang ditandai munculnya akar dan tunas. Kecambah tersebut diambil dan ditanam ke media tumbuh dalam wadah polybag ukuran $16 \mathrm{~cm} \times 20 \mathrm{~cm}$.

\section{Pemeliharaan bibit di polybag}

Kegiatan pemeliharaan bibit di polybag yaitu dengan melakukan penyiraman,menggunakan air biasa, penyiraman bibit dilakukan dua kali dalam satu hari pada waktu pagi dan sore hari selama 3 bulan dengan menggunakan sprayer.

\section{Pengambilan data pertumbuhan tanaman}

Pelaksanaan pengambilan data pertumbuhan tanaman yaitu data yang diambil berupa diameter dengan mengunakan alat mikrocaliper dan tinggi batang pada bagian yang diukur, $2 \mathrm{~cm}$ dari permukaan tanah di polybag hingga bagian bebas cabang tanaman, dilakukan pengukuran 3 kali selama 3 bulan.

Data pengukuran menggunakan rumus umum (Dajan, 1986); adalah berupa tinggi rata-rata dan diameter ratarata yaitu:

$$
\bar{h}=\frac{h_{1}+h_{2} \ldots+h_{n}}{n}
$$

Keterangan:

$\bar{h}=$ Tinggi rata-rata pengukuran batang bibit

$\mathrm{h} 1+\mathrm{h} 2 \ldots .+\mathrm{hn}=$ Nilai pengukuran tinggi batang bibit per tanaman

$\mathrm{n}=$ Jumlah bibit

Keterangan:

$$
\bar{d}=\frac{\mathrm{d} 1+\mathrm{d} 2 \ldots+\mathrm{d} n}{n}
$$

$\bar{d}=$ Diameter rata-rata pengukuran batang bibit

$\mathrm{d} 1+\mathrm{d} 2 \ldots+\mathrm{dn}=$ Nilai pengukuran diameter batang bibit per tanaman $=$ Jumlah bibit

Analisis data

Mengunakan Statistical Package for the Social Sciences (SPSS), dengan uji lanjut Duncan

HASIL DAN PEMBAHASAN

HASIL

Tabel 1. Hasil Analisis ANOVA Pertumbuhan Diameter

\begin{tabular}{|c|c|c|c|c|c|}
\hline \multicolumn{6}{|c|}{ Dependent Variable: Diameter } \\
\hline Source & $\begin{array}{c}\text { Type III Sum of } \\
\text { Squares }\end{array}$ & Df & Mean Square & $F$ & Sig. \\
\hline $\begin{array}{l}\text { Corrected } \\
\text { Model }\end{array}$ & $3.864^{\mathrm{a}}$ & 2 & 1.932 & 179.412 & .000 \\
\hline Intercept & 64.543 & 1 & 64.543 & 5994.428 & .000 \\
\hline Media & 3.864 & 2 & 1.932 & 179.412 & .000 \\
\hline Error & 1.518 & 141 & 011 & & \\
\hline Total & 72.063 & 144 & & & \\
\hline Corrected Total & 5.382 & 143 & & & \\
\hline
\end{tabular}

Tests of Between-Subjects Effects 
Tabel 2. Hasil Analisis ANOVA Pertumbuhan Tinggi

Dependent Variable: Tinggi

Tests of Between-Subjects Effects

\begin{tabular}{lcrrrr}
\hline \multicolumn{1}{c}{ Source } & \multicolumn{1}{c}{ Type III Sum of } & & & & \multicolumn{1}{c}{ Sig. } \\
Corrected Model & Squares & Df & Mean Square & \multicolumn{1}{c}{ F } & \multicolumn{1}{c}{ S } \\
Intercept & $32626.9899^{\mathrm{a}}$ & 2 & 16313.495 & 238.256 & .000 \\
Media & 637611.596 & 1 & 637611.596 & 9312.232 & .000 \\
Error & 32626.989 & 2 & 16313.495 & 238.256 & .000 \\
Total & 9654.316 & 141 & 68.470 & & \\
Corrected Total & 699732.000 & 144 & & & \\
\hline
\end{tabular}

a. $R$ Squared $=.772$ (Adjusted $R$ Squared $=.768$ )

Tabel 3. Hasil Analisis ANOVA Pertumbuhan Jumlah Daun

Tests of Between-Subjects Effects

Dependent Variable: Jumlah Daun

\begin{tabular}{lrrrrr}
\multicolumn{1}{c}{ Source } & $\begin{array}{c}\text { Type III Sum of } \\
\text { Squares }\end{array}$ & Df & Mean Square & \multicolumn{1}{c}{ F } & \multicolumn{1}{c}{ Sig. } \\
\hline Corrected Model & $2374.448^{\mathrm{a}}$ & 2 & 1187.224 & 415.070 & .000 \\
Intercept & 20542.084 & 1 & 20542.084 & 7181.802 & .000 \\
Media & 2374.448 & 2 & 1187.224 & 415.070 & .000 \\
Error & 403.302 & 141 & 2.860 & & \\
Total & 24240.000 & 144 & & & \\
Corrected Total & 2777.750 & 143 & & & \\
\hline
\end{tabular}

a. $R$ Squared $=.855$ (Adjusted $R$ Squared $=.853$ )

Tabel 4. Hasil Analisis Uji lanjut Duncan Pertumbuhan Diameter

\section{Diameter}

$\underline{\text { Duncan }^{\mathrm{a}, \mathrm{b}, \mathrm{c}}}$

\begin{tabular}{lrrrrr}
\hline & & & \multicolumn{3}{c}{ Subset } \\
\cline { 3 - 6 } Media & $\mathrm{N}$ & & 1 & 2 & 3 \\
\hline Overburden (OB) & & 44 & .4359 & & \\
OB + Pupuk Daun & 50 & & .7610 & .8152 \\
Top Soil & 50 & & & 1.000 & 1.000 \\
Sig. & & & 1.000 &
\end{tabular}

Means for groups in homogeneous subsets are displayed.

Based on observed means.

The error term is Mean Square (Error) $=.011$.

a. Uses Harmonic Mean Sample Size $=47.826$.

b. The group sizes are unequal. The harmonic mean of the group sizes is used. Type I error levels are not guaranteed.

c. Alpha $=0.05$. 
Tabel 5. Hasil Analisis Uji lanjut Duncan Pertumbuhan Tinggi Tinggi

Duncan $^{\mathrm{a}, \mathrm{b}, \mathrm{c}}$

Ting

\begin{tabular}{|c|c|c|c|}
\hline \multirow[b]{2}{*}{ Media } & \multirow[b]{2}{*}{$\mathrm{N}$} & \multicolumn{2}{|c|}{ Subset } \\
\hline & & 1 & 2 \\
\hline Overburden (OB) & 44 & 44.9091 & \\
\hline OB + Pupuk Daun & 50 & & 76.5800 \\
\hline Top Soil & 50 & & 78.5000 \\
\hline Sig. & & 1.000 & .258 \\
\hline
\end{tabular}

Means for groups in homogeneous subsets are displayed.

Based on observed means.

The error term is Mean Square (Error) $=68.470$.

a. Uses Harmonic Mean Sample Size $=47.826$.

b. The group sizes are unequal. The harmonic mean of the group sizes is used. Type I error levels are not guaranteed.

c. Alpha $=0.05$.

Tabel 6. Hasil Analisis Uji lanjut Duncan Pertumbuhan Jumlah Daun Jumlah Daun

\begin{tabular}{|c|c|c|c|c|}
\hline \multicolumn{5}{|l|}{$\overline{\text { Duncan }} \overline{\mathrm{a}, \mathrm{b}, \mathrm{c}}$} \\
\hline \multirow[b]{2}{*}{ Media } & \multirow[b]{2}{*}{$\mathrm{N}$} & & ibset & \\
\hline & & 1 & 2 & 3 \\
\hline Overburden (OB) & 44 & 6.1364 & & \\
\hline OB + Pupuk Daun & 50 & & 14.2600 & \\
\hline Top Soil & 50 & & & 15.5000 \\
\hline Sig. & & 1.000 & 1.000 & 1.000 \\
\hline
\end{tabular}

Means for groups in homogeneous subsets are displayed.

Based on observed means.

The error term is Mean Square (Error) $=2.860$.

a. Uses Harmonic Mean Sample Size $=47.826$.

b. The group sizes are unequal. The harmonic mean of the group sizes is used. Type I error levels are not guaranteed.

c. $A$ lpha $=0.05$

\section{PEMBAHASAN}

Media tumbuh tanaman sengon buto (Enterolobium cyclocarpum Griseb) di fase tingkatan semai berdasarkan analisis ANOVA dan uji lanjut Duncan berpengaruh terhadap pertumbuhan diameter, tinggi dan jumlah daun tanaman. Pertumbuhan diameter semai pada media yang berbeda menghasilkan diameter yang berbeda, pertumbuhan diameter pada media overburden dicampur pupuk daun dibandingkan dengan media top soil, lebih besar dari pertumbuhan diameter media overburden dan lebih kecil dari pertumbuhan diameter media top Soil. Pertumbuhan tinggi semai pada media overburden dicampur pupuk daun menghasilkan tinggi rata-rata relatif sama atau mempunyai pengaruh yang sama dengan media top soil dan menghasilkan tinggi yang berbeda dengan media overburden. Ketiga media berpengaruh terhadap pertumbuhan banyak jumah daun disetiap media tumbuh, pada media overburden dicampur pupuk daun lebih banyak jumlah daunnya dibandingkan dengan media overburden namun lebih sedikit dibandingkan dengan media top soil. Hal ini sejalan dengan Mansur dan Adiwicaksono (2013), menyatakan pertumbuhan diameter dan tinggi tanaman di pengaruhi secara nyata 
oleh besaran dosis pupuk yang diberikan di lahan pasca tambang batubara. Selain itu Yan., Dkk (2016), menyatakan bahwa ketersediaan unsur hara tanah menjadi sangat penting untuk memberikan umpan balik positif terhadap pertumbuhan tanaman, serta menurut Wasis dan Alkautsar (2019), mengatakan bahwa perlakuan penambahan pupuk pada media akan meningkatkan pertumbuhan bibit sengon buto. Hilwan., Dkk (2013), menyatakan kemampuan jenis tanaman sengon buto dalam memberikan umpan balik positif terhadap perbaikan material atau media tanam di lahan pasca tambang. Karyati., Dkk (2018) menyatakan bahwa upaya dalam kegiatan revegetasi pada lahan pasca tambang dapat memperbaiki sifat-sifat tanah, memulihkan kesuburan tanah, dan memperbaiki iklim mikro tanah.

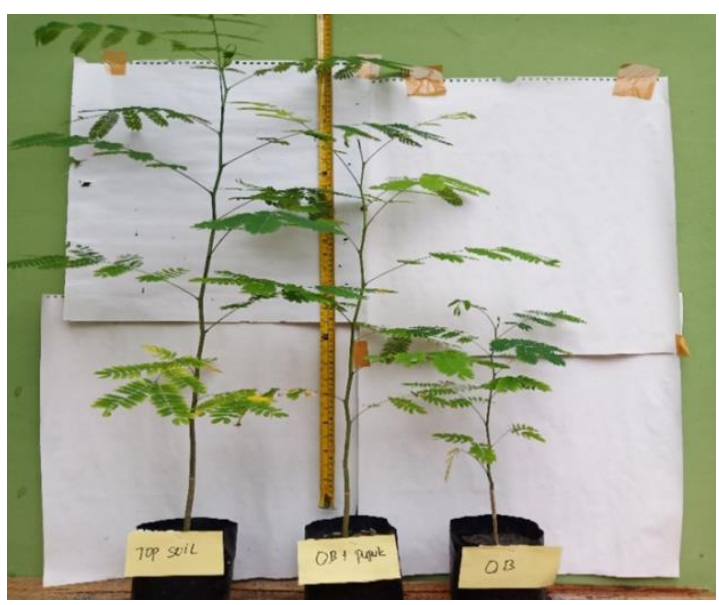

Gambar 1. Respon media pada pertumbuhan tanaman

\section{KESIMPULAN}

Kondisi pertumbuhan tanaman
dipengaruhi oleh media tumbuh,
pertumbuhan tanaman sengon buto
(Enterolobium cyclocarpum Griseb), pada
media overburden dicampur pupuk daun
dari tanaman sengon buto lebih baik
dibandingkan dengan media overburden
dan memiliki kesamaan dengan media
top soil. Kegiatan revegetasi pada lahan
pasca tambang batubara sangat tepat

memilih jenis tanaman sengon buto, dikarenakan memiliki kemampuan untuk tumbuh dan adaptif terhadap lahan yang kondisi struktur tanahnya rusak, sehingga memberikan umpan balik positif terhadap perbaikan sifat-sifat tanah, memulihkan kesuburan tanah, dan memperbaiki iklim mikro tanah

\section{DAFTAR PUSTAKA}

Dajan. A. 1986. Pengantar Metode Statistik II. Penerbit LP3ES. Jakarta.

Hilwan. I., D. Mulyana., W. G. Pananjung. 2013. Keanekaraaman Jenis Tumbuhan Bawah pada Tegakan Sengon Buto (Enterolobium cyclocarpum Griseb.) dan Trembesi (Samanea saman Merr.) di Lahan Pasca Tambang Batubara PT Kitadin, Embalut, Kutai Kartanagara, Kalimantan Timur. Jurnal Silvikultur Tropika Vol. 04. Hal. 6-10 ISSN: 2086-8227.

journal.ipb.ac.id/index.php/jsilvik/artic le/download/6923/5394/0

Karyati., R. O. Putri., M. Syafrudin. 2018. Suhu dan Kelembaban Tanah Pada Lahan Revegetasi Pasca Tambang di PT Tambang di PT Adimitra Baratama Nusantara Provinsi Kalimantan Timur. Jurnal AGRIFOR Volume XVII Nomor 1. ISSN P: 14126885 ISSN O: 2503-4960 https://fahutan.unmul.ac.id/dosen/kar yati/publikasi

Mansur. I dan R. Adiwicaksono. 2013. Pertumbuhan Samama, Jabon, dan Sengon Buto di Lahan Bekas Tambang Batubara PT. Tunas Inti Abadi, Kalimantan Selatan. Jurnal Silvikultur Tropika Vol. 04. Hal. 150159 ISSN: 2086-8227 journal.ipb.ac.id/index.php/jsilvik/artic le/download/8968/7020/0.

Murtinah. V., Marjenah., A. Ruchaemi., D. Ruhiyat. 2015. Pertumbuhan Hutan Tanaman Jati (Tectona grandis Linn.f.). Jurnal AGRIFOR. Volume 2. ISSN:1412-6885.http://ejurnal.untagsmd.ac.id/index.php/AG/article/view/ 1435

Sudarmadji., T dan W. Hartati. 2013. Upaya Pemulihan dan Potensi Keterpulihan Lahan Pasca Tambang 
Batubara. Proseding Seminar Hasilhasil Penelitian. Kementrian lingkungan Hidup dan Kehutanan. Badan Penelitian Pengembangan dan Inovasi. Balai Penelitian Teknologi Konservasi Sumber Daya Alam. ISBN: 978-602-17988-5-0. Hal. 11-23. http://balitekksda.or.id/wpcontent/uploads/2018/08/9Prosiding-Reklamasi-Lahan-PascaTambang.pdf

Wasis. B dan I. Alkautsar. 2019. Respon Pertumbuhan Bibit Sengon Buto (Enterobium cyclocarpum Griseb)
Pada Media Tailing PT Antam Pongkor Dengan Penambahan Arang Batok Kelapa dan Bokashi Pupuk Kandang. Jurnal Silvikultur Tropika. Volume 10 No 03. Hal 184191. ISSN 2086-8227. https://journal.ipb.ac.id/index.php/jsilv ik/article/view/31945/20228

Yan.T., Lu.X., Yang.K., Zhu.J. 2016. Leaf Nutrient Dynamics and Nutrient Resorption: a Comparison Between Larch Plantations and Adjacent Secondary Forests in Northeast Cina. Jurnal of Plant Ecology. https://doi.org/10.1093/jpe/rtv034 